\title{
Modelling adult skills in OECD countries
}

\author{
Rosario Scandurra \\ Departamento de Sociología, Universitat de Barcelona \\ e-mail: scandurra@ub.edu
}

\section{Jorge Calero}

Universitat de Barcelona \& IEB

e-mail: jorge.calero@ub.edu

\section{- Abstract}

Research in the social sciences has focused extensively on the relationship between family background, educational attainment and social destination, on the one hand, and on the processes of skills creation and skills use, on the other. This paper brings these two branches of the literature together by examining the correlation between a range of social factors. The methodology we adopt provides a comprehensive approach to the study of the channels through which literacy skills are acquired, taking into account the interrelation of family background, educational attainment, and the use of skills at work and at home. We use the Programme of International Assessment of Adult Competences (PIAAC) dataset and apply a structural equation model (SEM). Our results show that family background and education play an important role in the configuration of adult skills and skill practices. Unequal family access to resources has a strong impact at later stages in life and strongly affects educational attainment and skills outcomes. Additionally, skills use has a positive and direct impact on adult skills.

Keywords: Skills, education, family background, SEM, literacy, PIAAC

\section{Introduction}

In the last few decades, technological upgrading and an expanding knowledge-based economy have accelerated the transformation towards a high-skills equilibrium, which has brought about a radical shift in the labour profile from physical to intellectual-creative work. New technology eliminates jobs via increasing levels of automation, but it is unclear whether there has been a concomitant growth in the creation of high skilled employment. Some argue that the added value of this new economy lies in the competition of new ideas, knowledge and skills, as opposed to the accumulation of material capital (Hanushek \& Kimko 2000; Hanushek \& Wößmann 2008). At the same time, globalization places strict limits on a country's ability to intervene in its economy, thus enhancing international 
competition. The only way to maintain productivity and the standard of living seems to be to focus on high value added goods and services, based on the application of knowledge, skills and entrepreneurial ideas (Brown, Lauder, \& Ashton, 2008; ILO, 2011).

For these reasons, investing in education is considered to be one of the few effective policy strategies for global competitiveness and for meeting the demand for a high-skilled labour force. The Organisation for Economic Co-operation and Development (OECD) Skills Strategy and the report on literacy in the EU Act Now! (EU high level group of experts on literacy 2012; OECD 2013a) set these political objectives as their strategic goals. Greater participation in education is one way to meet the demands of the changing economy and, in some OECD countries, more than half the population aged between 25 and 34 has tertiary education. As Brown, Lauder, \& Ashton (2011) have demonstrated, the new settlement between the individual and the state is increasingly based on a skills nexus. Thus, while the state is responsible for providing the opportunity to develop and acquire skills and education as tools for securing social justice and social cohesion, individuals need to find employment for themselves and to sell their skills and knowledge in the global labour market (Brown et al. 2011; Reich 1992).

This study seeks to disentangle the channels via which skills are acquired and it does so by focusing on the interrelations established across multiple social spheres. As such, the main aim of this paper is to validate a common hypothetical model of the acquisition of adult skills for all OECD countries. Although, many studies have found both within- and between-country variations in adult skills, there are sufficient similarities across the OECD to suggest we might be able to corroborate a general skill-formation model. However, we should acknowledge from the outset that our findings are not specific to any one country participating in the Programme of International Assessment of Adult Competences (PIAAC). To test whether common tendencies can be identified in the acquisition of skills, we use the maximum information available in the dataset. In the framework developed herein, social spheres constitute the context in which skills are acquired and include family background, educational attainment, and use of skills at work and at home.

Research in the social sciences has focused either on the relationship between family background, educational attainment and social destination, or on the process of skills creation and use and the way to conceptualize the relationship between the individual and skills. Our paper seeks to merge these two branches of literature and to analyse their interactions. We avoid any interpretations that see these social phenomena as having 
single, direct effects, given that all the dimensions of interest typically intervene in the underlying process. In this sense, educational attainment mediates our model of skills acquisition. For this analysis, we use the PIAAC dataset and we apply structural equation models (SEMs). The use of cross-sectional data is an obvious limitation for the detection of causal mechanisms and for disentangling the possible mechanisms of skills acquisition. However, the robustness of our results relies on the validity of the theoretical model, as justified by the literature.

Our results show that the role played by education is highly relevant in the configuration of adult skills. Education affects literacy directly and it has a strong influence on the practice of skills. Furthermore, structural elements, including family background, play an important role in shaping education, skills use in the workplace and in daily life. A relevant residual influence of family background is associated with adult skills, indicating that unequal access in the family to resources has a strong effect at later stages in life and strongly affects education and skills outcomes. Yet, skills practice and use have a significant and positive effect on literacy and this clearly points to the potential benefits of lifelong learning policies.

From a general policy perspective, it is critical to understand the role of education and social factors in the development of adult skills. Although unequal access to education affects literacy, active life-long learning policies, with objectives that are clearly compatible and integrated with individual aspirations, can allow for subsequent interventions.

The rest of the paper is organized as follows. First, we briefly present the way in which skills are conceptualized and measured, then we discuss the social factors affecting the skills included in our model and, in section 4 , we consider the data and procedure used in the estimation process. Finally, in section 5, we discuss the results and conclusions.

\section{Conceptualization and measurement of skills}

Many empirical studies have shown skills to be an important predictor of socioeconomic success (Cunha et al. 2010; Hanushek et al. 2013; Cunha \& Heckman 2007); yet, the definition of skills remains a highly contentious question in the social sciences (note, that we use the term skills in the plural, since they have been shown to be multiple in nature), though it is agreed they are intrinsically dynamic, being made up of various stages of acquisition and proficiency. It should be borne in mind that our results are based on a global assessment survey, which means our measurement of skills is only partial and is a 
proxy of literacy core skills at a given moment in time. The skills evaluated are taken from the theoretical framework of the PIAAC.

PIAAC is a large-scale assessment that seeks to test adult skills, commissioned by the OECD. The antecedents of this programme were the International Adult Literacy Survey (IALS) (1994-98) and the Adult Literacy and Life Skills (ALL) Survey (2004-06). These programs aim to establish a benchmark of the "output" (or social outcomes) of the education and training systems by developing a comparable measure of skills performance. Global assessments of this kind are becoming more and more influential in international policy making and are an important tool in the reform of education and training systems (Meyer \& Benavot 2013; Grek 2010). Moreover, they are rapidly establishing themselves as a tool of governance that can influence the decisions of the actors involved (Grek 2009; Espeland \& Sauder 2007). In this paper, we consider PIAAC as a source of valuable information for comparative analyses but do not repeat discussions concerning the reliability of its skills measurement ${ }^{1}$, but refer the reader to the PIAAC technical report (OECD 2013b) for a full discussion.

The foundational skills assessed in PIAAC are a core set that are assumed to be essential for an individual to function in the knowledge economy. A major advantage here is that information is gathered about the skills that are actually rewarded in the labour market. Moreover, these skills are considered to be relevant in order to build higher order skills and to facilitate the retraining of individuals. In keeping with this aim, PIAAC adopts a "competence" approach - where competence is defined as the ability to apply knowledge and skills across environments and in interactive contexts that involve understanding, reflection and judgement (OECD, 2012) - and explores whether people are able to implement their knowledge in multiple contexts.

The skill domains assessed in PIAAC are literacy, numeracy, and problem solving in technology-rich environments. Literacy and numeracy are evaluated using 58 and 56 items, respectively, distributed across three main task characteristics (medium, context and aspect) and differentiated between paper and computer-based questions (OECD, 2013b). As in other international educational assessments, PIAAC uses item-response techniques (IRT) to generate ten plausible values of each domain examined.

This paper focuses specifically on literacy skills, defined as "understanding, evaluating, using and engaging with written texts to participate in society, to achieve one's

\footnotetext{
${ }^{1}$ Further information on measurement can be found in Gebhardt \& Adams, 2007; Goldstein, 2004; Svend, 2011.
} 
goals, and to develop one's knowledge and potential" (OECD 2012; Gal \& Tout 2014). The measure is used as a proxy of the sum of using, interpreting and understanding prose and qualitative information. However, the delimitation of a skills standard is generally questioned, since the construction of any statistical object implies the definition of a finite class of equivalences based on a given taxonomy (Desrosières 2008; Grek 2010; Lamont 2012). For this reason, the definition of a complex, dynamic concept, such as core skills, is extremely critical and has been extensively debated (Andrew et al., 2014; Espeland \& Sauder, 2007; Goldstein, 2004).

\section{Factors influencing the acquisition of skills and a hypothetical model}

Our aim is to provide a comprehensive picture of the social factors affecting the configuration of adult skills in OECD countries. The link between educational attainment and quality of schooling has been extensively analysed, but some authors identify a misspecification of this link (Wößmann 2003). Here, we consider the extent to which educational attainment serves as a gauge of adult skills and how their everyday use correlates with individual adult skills. Many factors affect skills acquisition and loss, and the interaction of these factors highlights the need for a complex analytical approach. The daily use of skills and educational attainment are strongly associated with adult skills, but a range of other prior factors also strongly correlate with the former.

Family background is deemed to affect both education and social destination directly and indirectly, as the social mobility literature has demonstrated (Bukodi \& Goldthorpe, 2013). Drawing on the cross-national PIAAC survey, we propose a comprehensive approach to the analysis of the way in which adult skills are configured. We examine the relationship between skills, their use in daily life and in the workplace, family background, and a range of socio-demographic covariates.

First, we examine whether the model as stated is suitable for all the OECD countries included in PIAAC. Then, we test the correspondence between education, use of skills in daily life and in the workplace and the literacy skills of the adult population, examining all the direct and indirect effects between them. Antecedents, such as family background, affect individual education positively and are strongly linked to skills use in the workplace and to literacy. In the model, we include the covariates of age, gender, being foreign born and home language, which have relevant direct and indirect effects on the configuration of skills. 
In the following sections, we introduce the factors associated with skills and briefly review previous theories forwarded in the literature regarding the variables included in the hypothetical model. We present the components that are central to our study of the configuration of skills: education, family background, use of skills in the workplace and use of skills in daily life. We also review the model's covariates of gender, age, being foreign born and home language. Finally, we present the hypotheses together with a graphical representation of the model.

\section{Education}

In the social sciences, distinct approaches have upheld the importance of education credentials as a determinant for a wide array of social outcomes, including those related to the labour market, income and social prestige. Since the development of the status attainment model (Blau \& Duncan 1967) and the Wisconsin model of education and early occupation attainment (Haller \& Portes 1973), a strong, positive association between education, social origin and individual occupation has been found (Kerckhoff 2001; Carbonaro 2007). Higher education attainment is also associated with higher earnings and incomes (Barone \& Van de Werfhorst, 2011; Hanushek et al., 2013; Harmon, Oosterbeek, \& Walker, 2003), better health, a higher level of wellbeing, and political participation (De Witte et al. 2013; Braga et al. 2013; Oreopoulos \& Salvanes 2011; Hoskins et al. 2014).

Various authors have examined the mechanisms thought to underpin these relations. Functionalists (Davis \& Moore 1945; Bell 1999) argue that the labour market needs diversified skills, which are linked to individual levels of qualification. Human capital theorists (Becker 1964) contend that the better educated enhance their individual skills and, hence, productivity, considering education to be a proxy for unmeasured skills. On the other hand, structuralists deem critical education to be a positional good, where education and skills are valuable to the extent that they offer greater access to a higher position in the job market. This perspective is shared by signal theorists (Spence 1973; Arrow 1973), who assert that education acts as a filter in the hiring process and is an imperfect measure of performance ability. Hence, rewards are based both on formal qualification and productivity. Others (Thurow 1975) point out that skills are mostly acquired in the workplace and the relation between education, skills and productivity depends more on the position in the job market than on educational attainment (labour market queue theory).

On the other hand, more radical approaches, such as that proposed by the credentialists (Collins, 1979), claim that the expansion of educational attainment does not 
contribute to an increase in overall competences. Rather, a higher education qualification operates as a device of macro-social motivation to justify wage discrepancies in the labour market. All these theories recognize that both education and skills constitute an advantage for individual success, but they tend to disagree upon which factor is the most important. Thus, they diverge with regard to the level of correspondence between education, skills and labour market demands.

In our analysis, we disentangle these relationships and consider skills as being the final outcome of the process and the interaction of multiple components. In this respect, skills acquisition is complex and multi-causal, passing through various stages, the process being socially and specifically determined. Additionally, the development of skills involves a continuum of gain and loss over the life cycle. In order to capture this process, we would need a panel of individuals and repeated measures of their skills over the life cycle. To our knowledge, this type of data is as yet unavailable.

\section{Family background}

The importance of family origin as a determinant of educational achievement and skills has been monitored from the 1960s and '70s (Coleman 1966; Bourdieu \& Passeron 1964; Boudon 1973) until the present day (Black et al. 2005; Chevalier et al. 2013). The accessibility and allocation of different forms of family capital directly and indirectly influence an individual's status at a later stage in their life (Blau \& Duncan 1967; Erikson \& Goldthorpe 1992; Breen \& Karlson 2014). Parental social and financial capacity and their incentives to invest in their offspring's education are prominent in this process (Jerrim \& Macmillan 2015). Parental education has an indirect effect on children's access to material and immaterial resources and their related quality within their family and this may consequently influence schooling decisions. This association has been described in the literature of social mobility as the intergenerational transmission of education.

It has proved difficult to differentiate between genetic transmission (nature) and environmental determinants (nurture) and this distinction may even be obsolete (Cunha et al. 2010; Heckman 1995), as demonstrated from the last two decades of epigenetics research. An unexplained residual effect between parental education and skills, having controlled for education, shows the extent to which skills are related to family background. This could have both a nature and a nurture component. For this reason, we interpret this coefficient as the unaccounted (via education) effect of family origin on individual skills. Moreover, as the literature on social mobility shows, there is also an intergenerational 
transmission of social destination, demonstrated by the high correlation between family background and the occupational status of offspring. In our model we consider the level of skills use of the individual in the workplace as a proxy of their current job. We discuss this claim in the next section.

\section{Skills use}

Practice engagement theory suggests that individuals acquire skills through participation in multiple specific practices. Related to this is the 'use it or lose it' hypothesis (Krahn \& Lowe 1998). Individuals practice their skills daily with varying frequency and intensity, which influences the mastery (or deterioration) of their skill set. Moreover, the extent to which an individual acquires skills is well represented by the dichotomy presented by Guile \& Okumoto (2007) between generic/transferable and context-specific skills (i.e., that determined practice generally is 'situated' in a specific environment). This latter position also represents the views of seminal thinkers such as Collins and Evans (2007) and Flyvberg (2001), who argue that it is only by developing context specific 'deep' (tacit) understanding that one can gain expertise. They also contend that much tacit knowledge is socially facilitated and is only gained through immersion in groups that already possess this knowledge (i.e., immersion with those already undertaking the role). A successful gain of tacit knowledge requires individuals effectively embedding themselves within the social group that embodies such specific expertise.

In our model, we distinguish skills practices in two separate dimensions: in the workplace and in daily life (at home). This construct is designed to measure the job related tasks reported by the interviewees, but it could be interpreted as a proxy for the use of intensive skills in the workplace. The latent variable of skills use in the workplace could be related to the individual occupation classification, although it is not based on relative measures of position and prestige in the labour market, for instance experience in the workplace, the occupation sector or the international occupation classification. The underlying hypothesis is that the actual use of skills in the workplace is a better proxy for the occupation status and prestige in the labour market. In fact, it is increasingly difficult in contemporary society to discriminate between very similar jobs. Most cross-national research adopts diverse occupational classifications, but when studying the occupation category the current job is not specifically considered. Occupation and job are not equivalent units of analysis, since the former is simply an aggregation of the latter (Baron \& Bielby 1980). In addition, each occupation category is intrinsically highly 
heterogeneous, much more so than most researchers have hitherto assumed.

For these reasons, in our model, we draw on the actual use of skills in the workplace rather than the individual occupation characteristics. Making use of these proxies enhances cross-country comparability. Furthermore, the polychoric correlation between the latent constructs of skills use in the workplace and the international classification occupation (ISCO) was above 0.8 in all the countries examined.

\section{Gender}

Various studies show marked gender differences in performance in mathematics and reading. Analyses of global international assessments (i.e., PISA) show that boys outperform girls in mathematics, while girls do better at reading. The evidence, however, is mixed and these differences are inversely correlated across the four waves of PISA between and within countries (Stoet \& Geary 2015). Theoretical explanations relate these gaps to biological and socio-cultural causes, but research indicates the difficulty in isolating the two and reaffirms that both are important. In PIAAC, men outperform women in all three domains, that is, literacy, numeracy and problem solving, but after controlling for age and diverse social characteristics, these gaps seem likely to disappear. Furthermore, we should recognise that gender diversity in cognitive and personality traits affects the acquisition and loss of key skills, yet, these sources of difference lie beyond the scope of this paper. Gender might, on the other hand, be associated with unequal access to the labour market. After taking this difference into account, gender seems likely to have a nonsignificant effect on foundational skills. Moreover, a residual association of gender with education reflects unequal access to opportunities in education, which is partially related to a historical unequal access to schooling between the genders.

\section{Age}

The evidence indicates that foundational skills tend to be lower among older cohorts. This pattern is consistent across countries if we examine ALL and IALS (Desjardins \& Warnke 2012) results. Younger adults (aged 26-35) have higher skills in the three domains evaluated in PIAAC (Rammstedt et al. 2012). These results have both a biological explanation, related to ageing, and an explanation related to the asymmetrical access to education. Typically, in OECD countries, younger cohorts are exposed to longer periods in the education system than their older counterparts. It is likely that the greater amount of education received by younger cohorts has a more positive effect on their skills level than the corresponding effect on the levels of the older cohorts (Calero et al. 2016). 
A process of skills loss might result from the lack of training of a determined set of skills taught in the education system. In PIAAC, adults aged between 25 and 30 present an advantage of almost half a standard deviation in their skills scores, compared to those aged between 16 and 20. At the age of 45, skills deteriorate radically across all OECD countries. Since we are comparing multiple cohorts over a period of more than 30 years, we should take into consideration the heterogeneity of family backgrounds and the fact that younger people might have a richer family background. In fact, most of the countries participating in PIAAC have increased their overall level of educational attainment (education expansion) and this is most marked for the individuals interviewed and their parents.

\section{Foreign born and home language}

The gulf in the educational outcomes of foreign born and the native population has been well documented. Many studies rely on explanations at the individual level that focus, above all, on the ascribed characteristics of cultural positions or the structural features of immigrant environments (Marks 2006). An examination of cross-national studies suggests that the gap might also reflect macro-institutional factors, such as education systems and migration policies (Dronkers \& Heus 2013; Dronkers \& Velden 2013). These authors show that, in traditional immigration destinations, immigrant and native educational performances are similar. They also link these findings with the idea of a reduced social distance.

When examining adult skills, there are two main sources of disparity. One concerns the discrepancy within each country's education system and the difference in skills of foreigners and natives entering the labour market. The second factor is that the foreign born population is, in general, likely to have a poorer family background than that of natives.

Moreover, in relation to educational performance, command of the relevant national language is a critical resource in promoting an individual's integration. In this sense, nonnatives are likely to be at a disadvantage, a circumstance that varies depending on linguistic distance, exposure to the host country's language and their date of arrival in the country (Isphording 2014).

\section{Model hypotheses and graphical representation}

Figure 1 is a graphical representation of the proposed model. Above, we have presented existing theories regarding the relationship between the variables included in the model. We expect parental education to have a positive effect on offspring education 
(intergenerational transmission of education). Besides, an unexplained residual effect between parental education and skills demonstrates the extent to which skills are related to family background. Education has a positive and direct effect on literacy and on the practice of skills both in the home and in the workplace. In addition to this direct effect, a relevant mediating effect of these dimensions might have an influence on skills. Both skills practices have a positive effect on foundational skills. We control for different covariates and we expect a direct and negative effect of age on literacy. 
Figure 1. Path diagram, visual representation of the model

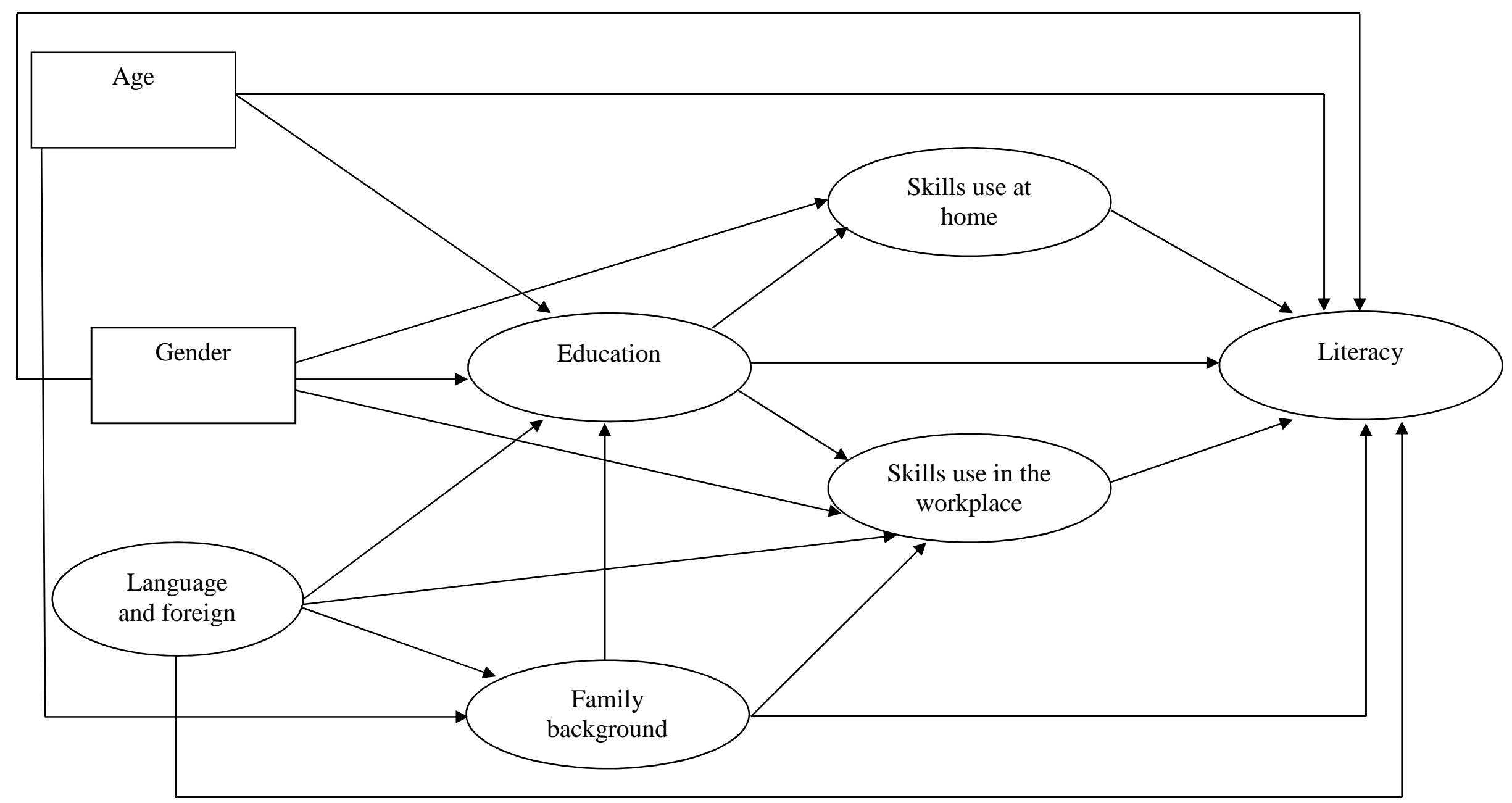

*Circles represent the latent variables and rectangles the observed variables. 


\section{Data and methods}

The study is based on the first wave of PIAAC, released in October 2013 and updated in March 2015. The data are made available on the OECD webpage and were retrieved in April 2015. PIAAC provides direct measures of skills together with rich information on the individual social environment for adults aged between 16 and 65 in 24 countries, mostly OECD members.

For the purposes of this analysis, we limited the sample to the population aged between 25 and 55, who reported having an occupation when the survey was conducted. Those aged between 16 and 25 were excluded, because of the likelihood of their still being in higher education. Additionally, those aged 56 and over were omitted, because of their being close to the age of retirement (depending on country legislation) and the likelihood of their having missing data on skills use in the workplace. We restricted the sample, therefore, to workers aged between 25 and 55, in order to have the best estimate of the skills structure of the active population. A robustness analysis confirmed the relevance of this sample restriction. Australia and Cyprus were excluded from the analysis owing to the public unavailability of data, and Russia for reasons of data quality and the absence of certain crucial variables used in the model. The final analytic sample consisted of 70,712 individuals who fulfilled the following criteria: workers aged 25 to 55, with full availability of data and good data quality. This is a highly select sample comprising individuals in work during one of the harshest moments of the Great Recession (i.e. 2011/2012). Indeed, the choice of this date had a marked influence on their probabilities of being employed in the labour markets analysed in the PIAAC. The sample analysed has a higher level of educational attainment and generally higher values for all the variables included in the analysis than those included in the country reference samples.

Our ultimate goal was to disentangle the effect of various social factors and to estimate the extent to which each of them contributes to the development of core literacy skills, while at the same time accounting for interacting effects. The empirical foundation of the model was based on the seminal paper by Desjardins (2003). The central part of the model was also based on the social mobility literature and the widely used social origineducation attainment-social destination triangle (E. Bukodi \& Goldthorpe 2012; Breen \& Karlson 2014). The main idea underpinning the model is that educational attainment mediates between family background and future social outcomes. 


\section{Selection of variables}

The four components of skills acquisition were measured as follows: family background using the father's highest level of educational attainment; education using two items; and the practice of skills in the workplace and in the home using four items. Below, we outline some of the decisions taken when selecting the variables to be used in the modelling process.

In line with much of the cross-national research literature, a collapsed threecategory scheme of father's education was used for the latent construct of the respondent's family background (descriptive statistics are presented in Table II). This variable represents a better proxy for family background especially because we consider those born between the late 1950s and the late 1980s. In general, parental education is deemed a good proxy for family background and social status. Scholars have also adopted other proxies of family background, including parental occupation or income. One example currently used in PISA is economic, social and cultural status (ESCS), which is a composite indicator derived from the International Socio-Economic Index (ISEI), a widely accepted classification of occupational status (Ganzeboom et al. 1992), parental years of schooling and three family resource indexes.

In PIAAC, as in most cross-national studies, there is no information about family income or parental occupation. The survey compiles information on the highest level of educational attainment of both parents and the number of books in the home when the respondent was 15 years old. Yet, as some authors claim, parental education might be preferable to other proxies of family background, because it captures a wide range of family inputs (Bukodi \& Goldthorpe, 2012).

The latent education variable was constructed using two items: one provides information about the number of years of education (quantity) and the other records the age when achieving the highest formal qualification on a categorical scale. The latter item - the age of the individual on completing their education - provides information on a number of relevant aspects. Respondents who obtain a given qualification at a given age are likely to have higher skills and a higher level of skills use in daily life than those who obtained it at a later point in their lives.

Years of schooling are directly converted from the information reported on the highest qualification attained. Since the focus is on the degree to which education affects skills and their use, we tend to maximize this effect by handling a continuous variable. Hence, we use the imputed years of education on a continuous scale and a categorical 
variable for age on completion. As Germany does not report information on the imputed years of education for its respondents, for this country, we applied a recodification on the basis of the ISCED level of individual qualification, as provided by the OECD Directorate of Education. For missing data in the case of the age on completing a qualification, we bypassed this lack of information by employing the multiple imputation technique, using the discrete variable of age and the covariates included in our model.

The latent variable of skills use in the workplace was based on four items: three record information about frequency of use of core skills (such as writing, numeracy and reading) and the fourth item captures the influence of these skills on the respondent's coworkers. The latent variable of skills use in daily life was constructed using records of skills use in the household. We included numeracy, reading, writing and the use of information technology. The items used to construct the latent factor are shown in Table $\mathbf{1 .}$ Many studies do not draw a distinction between the spheres of skills practice, basically because of their high correlation (OECD 2000). In our model, however, we opted to separate these two spheres of acquisition. The intensity of skills use was coded on the Likert scale and then log transformed.

Finally, the latent construct of literacy comprises the ten plausible values of literacy $^{2}$ as described in Section 2.

We also controlled for age, gender, being born outside the test country and home language. The latter was measured with a latent variable based on three dummy items: being born in the country, speaking the same language as that used on the assessment and being a native speaker. Figure 1 presents a path diagram of the model. A detailed list of the manifest and latent variables included in the model is given in Table $\mathbf{I}$.

\footnotetext{
${ }^{2}$ Treating the ten plausible scores as items of a latent variable is equivalent to estimating ten models separately and taking the mean of the parameters.
} 
Table I. Latent and observed variables used in the model

\begin{tabular}{|c|c|c|c|c|c|}
\hline \multicolumn{3}{|c|}{ Latent variables } & \multicolumn{3}{|c|}{ Observed variables } \\
\hline Symbol & Label & Abbreviation & Symbol & Description & Type \\
\hline$\xi_{1}$ & \multirow{5}{*}{$\begin{array}{l}\text { Language and foreign sta- } \\
\text { tus }\end{array}$} & Gender & $\mathrm{X} 1$ & gender & dichotomous \\
\hline$\xi_{2}$ & & Age & $\mathrm{x} 2$ & age & ordinal \\
\hline \multirow[t]{3}{*}{$\eta_{0}$} & & \multirow[t]{3}{*}{ F0 } & $\mathrm{y} 1$ & Born in country & dichotomous \\
\hline & & & $\mathrm{y}_{2}$ & Respondent is a native speaker & dichotomous \\
\hline & & & y3 & $\begin{array}{l}\text { Test language same as that of native lan- } \\
\text { guage }\end{array}$ & dichotomous \\
\hline$\eta_{1}$ & Family background & $\mathrm{F} 1$ & $\mathrm{y} 4$ & Father's Highest Level of Education & ordinal \\
\hline \multirow[t]{2}{*}{$\eta_{2}$} & \multirow[t]{2}{*}{ Education } & \multirow[t]{2}{*}{$\mathrm{F} 2$} & y5 & Highest Level Of Education & continuous \\
\hline & & & y6 & $\begin{array}{l}\text { Age When Obtaining Highest Qualifica- } \\
\text { tion }\end{array}$ & ordinal \\
\hline \multirow[t]{4}{*}{$\eta_{3}$} & \multirow[t]{4}{*}{ Use of skills at work } & \multirow[t]{4}{*}{$\mathrm{F} 3$} & $\mathrm{y} 7$ & Use Of Reading Skills At Work & ordinal \\
\hline & & & y8 & Use Of Numeracy Skills At Work & ordinal \\
\hline & & & y9 & Use Of Writing Skills At Work & ordinal \\
\hline & & & $\mathrm{y} 10$ & Use Of Influencing Skills At Work & ordinal \\
\hline \multirow[t]{4}{*}{$\eta_{4}$} & \multirow[t]{4}{*}{ Use of skills at home } & \multirow[t]{4}{*}{$\mathrm{F} 4$} & $\mathrm{y} 11$ & Use Of Reading Skills At Home & ordinal \\
\hline & & & $\mathrm{y} 12$ & Use Of Numeracy Skills At Home & ordinal \\
\hline & & & $\mathrm{y} 13$ & Use Of Writing Skills At Home & ordinal \\
\hline & & & $\mathrm{y} 14$ & Use Of ICT Skills At Home & ordinal \\
\hline \multirow[t]{10}{*}{$\eta_{5}$} & \multirow[t]{10}{*}{ Literacy proficiency } & \multirow[t]{10}{*}{ F5 } & $\mathrm{y} 15$ & Plausible value Literacy pvlit1 & continuous \\
\hline & & & $\mathrm{y} 16$ & Plausible value Literacy pvlit2 & continuous \\
\hline & & & $\mathrm{y} 17$ & Plausible value Literacy pvlit3 & continuous \\
\hline & & & $\mathrm{y} 18$ & Plausible value Literacy pvlit4 & continuous \\
\hline & & & $\mathrm{y} 19$ & Plausible value Literacy pvlit5 & continuous \\
\hline & & & $\mathrm{y} 20$ & Plausible value Literacy pvlit6 & continuous \\
\hline & & & $\mathrm{y} 21$ & Plausible value Literacy pvlit7 & continuous \\
\hline & & & $\mathrm{y} 22$ & Plausible value Literacy pvlit8 & continuous \\
\hline & & & y23 & Plausible value Literacy pvlit9 & continuous \\
\hline & & & y24 & Plausible value Literacy pvlit10 & continuous \\
\hline
\end{tabular}

\section{The modelling process}

To test the hypothesized relationships between the constructs and to evaluate the theoretical model, we used a structural equation model (SEM). This is a broadly flexible set of statistical techniques which allows the representation of the constructs of interest and the measurement of the extent to which the data are consistent with a proposed theoretical model. The advantages of SEM over conventional regression analysis techniques are basically four. SEM allows us to describe the directed dependence of a set of observed and unobserved (or latent) variables. Second, latent variables are also more reliable than observed variables, as measurement error is accounted for and they permit the combination of almost any kind of item independently of the type of measurement. Third, SEM allows 
the researcher to include multiple dependent variables and to use them in the interpretation of the model. Four, multiple goodness-of-fit measures are produced which allow us to evaluate just how well the model fits the data.

The variables' descriptive statistics are shown in Table IA in the appendix. Therefore, following the standard procedure in the SEM literature, our two-step modelling process included i) a measurement model, describing the way observed variables load onto latent constructs, and ii) a structural model, which estimates the pathways among all the variables, including the latent constructs (Kline 2016). A confirmatory factor analysis (CFA) was performed to check for the consistency of each latent variable (measurement model). The factor loading of each unobserved latent variable is given in Table II.

\section{Table II. Measurement model}

\begin{tabular}{|c|c|c|c|c|}
\hline & Estimate & S.E. & Est./S.E. & P-Value \\
\hline \multicolumn{5}{|l|}{ Measurement model } \\
\hline F0 $\leftarrow$ FOR_BORN & 0.865 & 0.063 & 13.626 & 0.000 \\
\hline N_SPEAK & 0.955 & 0.043 & 22.148 & 0.000 \\
\hline LANG_T & 0.921 & 0.044 & 20.959 & 0.000 \\
\hline $\mathrm{F} 1 \leftarrow \mathrm{FATED}$ & 0.72 & 0.002 & 458.721 & 0.000 \\
\hline $\mathrm{F} 2 \leftarrow \mathrm{YRSQUAL}$ & 0.944 & 0.006 & 159.498 & 0.000 \\
\hline B_Q01C1_C & 0.728 & 0.007 & 109.341 & 0.000 \\
\hline F3 $\leftarrow$ READH_C & 0.845 & 0.005 & 176.434 & 0.000 \\
\hline NUMH_C & 0.692 & 0.007 & 94.155 & 0.000 \\
\hline WRITH_C & 0.789 & 0.006 & 126.506 & 0.000 \\
\hline ICTH_C & 0.699 & 0.007 & 101.23 & 0.000 \\
\hline F4 $\leftarrow$ READW_C & 0.874 & 0.004 & 207.438 & 0.000 \\
\hline NUMW_C & 0.712 & 0.007 & 107.501 & 0.000 \\
\hline WRITW_C & 0.778 & 0.005 & 143.422 & 0.000 \\
\hline INFLW_C & 0.662 & 0.007 & 91.241 & 0.000 \\
\hline F5 $\leftarrow$ PVLIT1 & 0.941 & 0.002 & 581.245 & 0.000 \\
\hline PVLIT2 & 0.94 & 0.002 & 587.543 & 0.000 \\
\hline PVLIT3 & 0.939 & 0.002 & 565.691 & 0.000 \\
\hline PVLIT4 & 0.942 & 0.002 & 559.001 & 0.000 \\
\hline PVLIT5 & 0.94 & 0.002 & 533.185 & 0.000 \\
\hline PVLIT6 & 0.937 & 0.001 & 636.412 & 0.000 \\
\hline PVLIT7 & 0.94 & 0.002 & 484.739 & 0.000 \\
\hline PVLIT8 & 0.941 & 0.001 & 630.366 & 0.000 \\
\hline PVLIT9 & 0.943 & 0.001 & 803.557 & 0.000 \\
\hline PVLIT10 & 0.939 & 0.002 & 555.089 & 0.000 \\
\hline
\end{tabular}

We tested whether the items that constitute family background, education, use of skills at home and in the workplace load onto their respective latent constructs, and a full 
SEM was estimated to test the relationships between the latent variables and covariates. Throughout the process, we rescaled sample variance values of the continuous variables, as some exceeded the 1-to-10 range and this can generate convergence problems, especially with models that combine discrete and continuous outcomes.

The estimator selected was robust weighted least squares (WLSMV), created to deal especially with a combination of ordinal, discrete and continuous data and a small to medium sample size. All the SEM estimations were conducted using Mplus 7.4. We then scrutinized the modification indices and performed J-Rule using Jrule (Oberski 2009) which implements the method described in Saris, Satorra, \& van der Veld (2009). Thus, we aimed to determine whether the factor structure of our model was invariant across the OECD countries ${ }^{3}$. We performed sensitivity tests including missing data and recoding the zero category of manifest indicators in the latent constructs of use of skills into missing data. Bootstrap estimation was performed using 2,000 iterations, yielding the same results as the WLSMV estimation ${ }^{4}$.

\section{Results}

Good model fits were obtained for the pooled OECD countries $(\chi 2=2849.448, \mathrm{df}=281$, $\mathrm{p}<.01, \chi^{2} / \mathrm{df}=10.140$, comparative fit index $(\mathrm{CFI})=.976$, Tucker-Lewis index (TLI) $=.973$, root mean square error of approximation $($ RMSEA) $=.011)$. We report all the goodness-of-fit measures in the note to Table III. When the model was considered separately for each country, the fit indexes were consistent across all countries, with respect to the standard CFI and TLI thresholds. The RMSEA was also below .05, pointing to the plausibility of the model. In conclusion, we can reject the null hypothesis of a divergent structure of configuration of skills across OECD countries. It is important to stress that when interpreting these findings, we need to bear in mind that they refer to all countries participating in the PIAAC study.

The parameter estimates and the indirect effects, which have been standardized to facilitate comparisons, are reported in Table III. The path diagram is shown in Figure 2, but we exclude the measurement part of the model to enhance the figure's readability. Table IV in the appendix reports the results for numeracy. The estimates are very similar

\footnotetext{
${ }^{3}$ A test of measurement invariance (CFA) was performed for each country to check whether the OECD countries in PIAAC could be treated as a single group of countries.

${ }^{4}$ Sensitivity tests were performed by estimating the model with the exclusion of missing data. The results of both models present the same coefficient signs and sizes. The sensitivity analyses are available upon request from the authors.
} 
for both skill domains ${ }^{5}$. Problem solving was not included because this domain is not assessed in all the countries. Each structural parameter should be interpreted as a percentage change in the standard deviation of the dependent factor for a single change in the standard deviation of the independent factor under consideration, e.g., .2 should be interpreted as a $20 \%$ change. The results point to a strong effect of parental education on the individual's level of education, providing strong empirical evidence of the intergenerational transmission of education (standardized coefficient $782 \quad p<.01$ ). Moreover, family background has a residual effect on skills (standardized coefficient 254 $p<.01$ ), which is mediated by the model's other latent variables. This illustrates the extent to which family environment directly and indirectly affects skills in the long term, even after taking into account the individual education achieved and the other controls.

These results support the view that inequality in education and literacy is closely related to the resource inequality that exists between families of different social backgrounds. Age also has a negative association with the individual's family background (standardized coefficient -.242 $p<.01$ ) and an effect on education (standardized coefficient $.097 p<.01)$. Via family background, age affects education. In fact, younger individuals experienced a richer family environment, which has a positive effect in terms of educational achievement. This finding is in line with the belief that the increased access of younger age groups to education partially reduces the transmission of inequality in education.

The link between education and literacy was positive and significant (standardized coefficient $.188 p<.01)$. In addition, it has both a very strong association with skills use in daily life (standardized coefficient $.561 p<.01$ ) and on skills use in the workplace (standardized coefficient $.547 p<.01$ ). Education had a mediating effect on skills use in the workplace (standardized coefficient $.061 p<0.01$ ), and a slightly higher effect on those in daily life (standardized coefficient $.068 p<.01$ ). These results show that education is more relevant in explaining differentials in the use of skills in daily life and that these have an additive effect on literacy.

The practice of skills in the workplace and at home are very strongly correlated to each other (standardized coefficient $.509 p<.01$ ) and have a positive effect on literacy. This finding is in line with the literature, since both latent variables reflect the individual's daily

\footnotetext{
${ }^{5}$ The results for the two domains differ slightly at the second decimal point. Only one structural parameter differs: the effect of age on literacy is negative and significant, while for numeracy it is not. This points to less obsolescence of numeracy than of literacy skills.
} 
life practices, albeit differentiating them by place of use. Home practice had a stronger effect on literacy (standardized coefficient .121 $p<.01$ ), which is similar to the effect of the use of skills in the workplace (standardized coefficient $.112 p<.01$ ).

Women tend to use fewer skills in the workplace than men, but this difference was non-significant for the daily use of skills. Women are likely to have an advantage (standardized coefficient $.066 p<.01$ ) in terms of education, but this is not reflected by skills use in the labour market (standardized coefficient -.0127 $p<.01$ ). In addition, being foreign born and home language have a negative effect on literacy (standardized coefficient $-.228 p<.01$ ) and on the use of skills in the labour market (standardized coefficient -.098 $p<.01)$. Women and foreigners are likely to be employed in less skillintensive occupations, performing jobs whose demands are below those of their actual level of qualification. The indirect effects of gender and being foreign born on education are significant, but have a moderate association. These results demonstrate the unequal access to the labour market of women and foreign born individuals in the OECD area. 
Figure 2. Path diagram, visual representation of the model

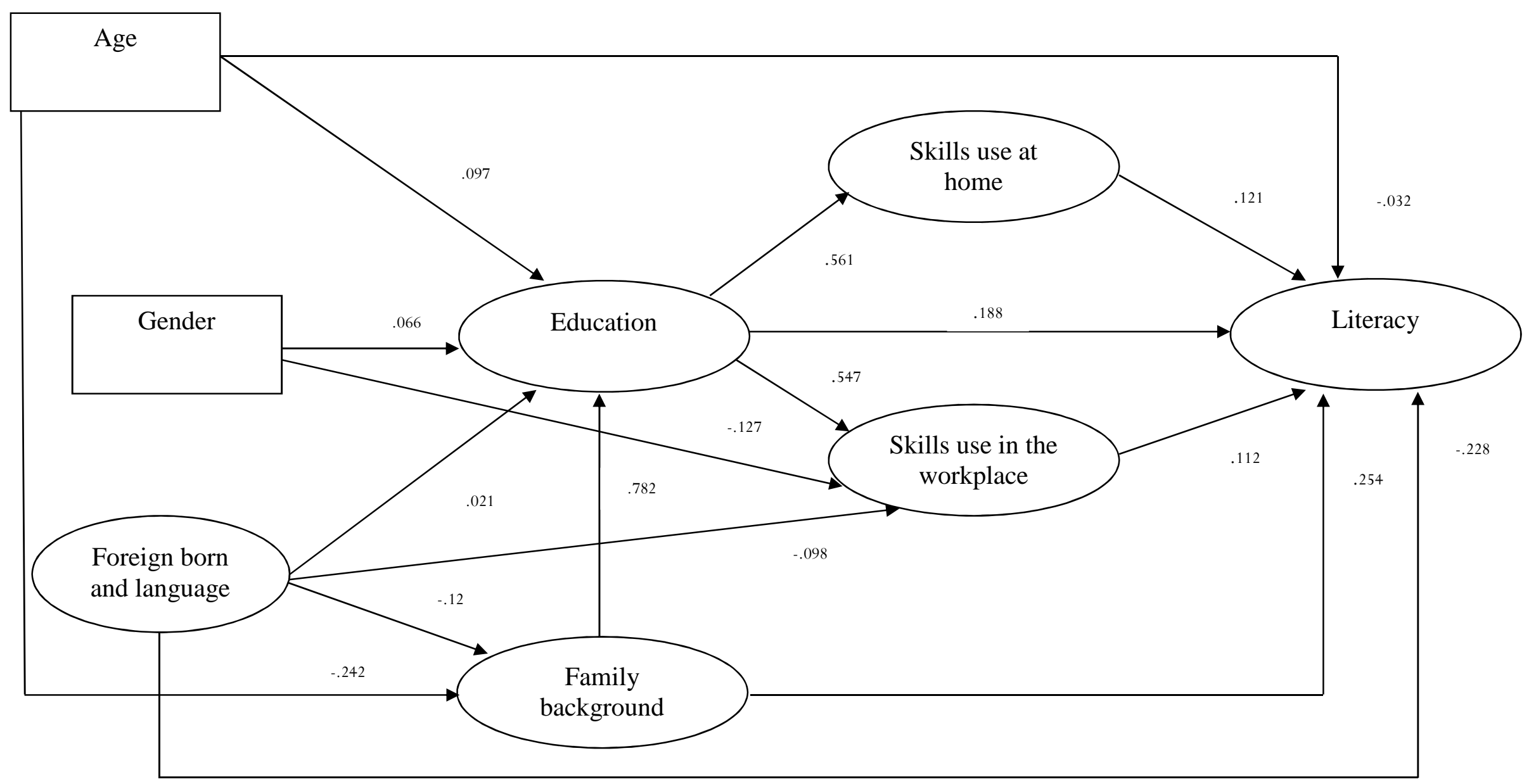

*Circles represent the latent variables and rectangles the observed variables. 
Table III. Model results

\begin{tabular}{|c|c|c|c|c|}
\hline & Estimate & S.E. & Est./S.E. & P-Value \\
\hline \multicolumn{5}{|l|}{ Structural parameters } \\
\hline $\mathrm{F} 0 \rightarrow \mathrm{F} 1$ & -0.12 & 0.02 & -5.891 & 0.000 \\
\hline $\mathrm{F} 1 \rightarrow \mathrm{F} 2$ & 0.782 & 0.014 & 57.041 & 0.000 \\
\hline $\mathrm{F} 0 \rightarrow \mathrm{F} 2$ & 0.021 & 0.009 & 2.391 & 0.017 \\
\hline $\mathrm{F} 2 \rightarrow \mathrm{F} 3$ & 0.561 & 0.007 & 77.909 & 0.000 \\
\hline $\mathrm{F} 2 \rightarrow \mathrm{F} 4$ & 0.547 & 0.023 & 23.559 & 0.000 \\
\hline $\mathrm{F} 1 \rightarrow \mathrm{F} 4$ & 0.044 & 0.027 & 1.639 & 0.101 \\
\hline $\mathrm{F} 0 \rightarrow \mathrm{F} 4$ & -0.098 & 0.009 & -11.483 & 0.000 \\
\hline $\mathrm{F} 4 \rightarrow \mathrm{F} 5$ & 0.112 & 0.015 & 7.594 & 0.000 \\
\hline $\mathrm{F} 2 \rightarrow \mathrm{F} 5$ & 0.188 & 0.032 & 5.797 & 0.000 \\
\hline $\mathrm{F} 3 \rightarrow \mathrm{F} 5$ & 0.121 & 0.012 & 9.82 & 0.000 \\
\hline $\mathrm{F} 1 \rightarrow \mathrm{F} 5$ & 0.254 & 0.036 & 7.136 & 0.000 \\
\hline $\mathrm{F} 0 \rightarrow \mathrm{F} 5$ & -0.228 & 0.016 & -14.387 & 0.000 \\
\hline Age $\rightarrow \mathrm{F} 1$ & -0.242 & 0.015 & -16.574 & 0.000 \\
\hline Age $\rightarrow \mathrm{F} 2$ & 0.097 & 0.016 & 6.161 & 0.000 \\
\hline Gender $\rightarrow \mathrm{F} 2$ & 0.066 & 0.008 & 8.708 & 0.000 \\
\hline Gender $\rightarrow \mathrm{F} 3$ & -0.012 & 0.009 & -1.42 & 0.156 \\
\hline Gender $\rightarrow \mathrm{F} 4$ & -0.127 & 0.008 & -15.145 & 0.000 \\
\hline Age $\rightarrow$ F5 & -0.032 & 0.01 & -3.272 & 0.001 \\
\hline Gender $\rightarrow$ F5 & -0.011 & 0.008 & -1.391 & 0.164 \\
\hline $\mathrm{F} 3 \leftrightarrow \mathrm{F} 4$ & 0.509 & 0.011 & 44.948 & 0.000 \\
\hline \multicolumn{5}{|l|}{ Indirect effects } \\
\hline Gender $\rightarrow$ F5 & -0.003 & 0.003 & -1.016 & 0.310 \\
\hline $\mathrm{GENDER} \rightarrow \mathrm{F} 3 \rightarrow \mathrm{F} 5$ & -0.001 & 0.001 & -1.396 & 0.163 \\
\hline $\mathrm{GENDER} \rightarrow \mathrm{F} 4 \rightarrow \mathrm{F} 5$ & -0.014 & 0.002 & -6.584 & 0.000 \\
\hline $\mathrm{GENDER} \rightarrow \mathrm{F} 2 \rightarrow \mathrm{F} 5$ & 0.012 & 0.003 & 4.5 & 0.000 \\
\hline $\mathrm{F} 2 \rightarrow \mathrm{F} 5$ & 0.129 & 0.008 & 15.729 & 0.000 \\
\hline $\mathrm{F} 2 \rightarrow \mathrm{F} 3 \rightarrow \mathrm{F} 5$ & 0.068 & 0.007 & 9.66 & 0.000 \\
\hline $\mathrm{F} 2 \rightarrow \mathrm{F} 4 \rightarrow \mathrm{F} 5$ & 0.061 & 0.009 & 6.677 & 0.000 \\
\hline $\mathrm{F} 1 \rightarrow \mathrm{F} 5$ & 0.253 & 0.022 & 11.613 & 0.000 \\
\hline $\mathrm{F} 1 \rightarrow \mathrm{F} 2 \rightarrow \mathrm{F} 3 \rightarrow \mathrm{F} 5$ & 0.053 & 0.006 & 9.106 & 0.000 \\
\hline $\mathrm{F} 1 \rightarrow \mathrm{F} 2 \rightarrow \mathrm{F} 5$ & 0.147 & 0.024 & 6.092 & 0.000 \\
\hline $\mathrm{F} 1 \rightarrow \mathrm{F} 2 \rightarrow \mathrm{F} 4 \rightarrow \mathrm{F} 5$ & 0.048 & 0.007 & 6.592 & 0.000 \\
\hline $\mathrm{F} 1 \rightarrow \mathrm{F} 4 \rightarrow \mathrm{F} 5$ & 0.005 & 0.003 & 1.713 & 0.087 \\
\hline $\mathrm{AGE} \rightarrow \mathrm{F} 5$ & -0.017 & 0.003 & -5.247 & 0.000 \\
\hline $\mathrm{AGE} \rightarrow \mathrm{F} 1 \rightarrow \mathrm{F} 2 \rightarrow \mathrm{F} 5$ & -0.036 & 0.006 & -5.681 & 0.000 \\
\hline $\mathrm{AGE} \rightarrow \mathrm{F} 2 \rightarrow \mathrm{F} 5$ & 0.018 & 0.004 & 4.338 & 0.000 \\
\hline $\mathrm{F} 0 \rightarrow \mathrm{F} 5$ & -0.025 & 0.004 & -6.96 & 0.000 \\
\hline $\mathrm{F} 0 \rightarrow \mathrm{F} 1 \rightarrow \mathrm{F} 2 \rightarrow \mathrm{F} 5$ & -0.018 & 0.003 & -5.544 & 0.000 \\
\hline $\mathrm{F} 0 \rightarrow \mathrm{F} 2 \rightarrow \mathrm{F} 5$ & 0.004 & 0.002 & 2.455 & 0.014 \\
\hline $\mathrm{F} 0 \rightarrow \mathrm{F} 4 \rightarrow \mathrm{F} 5$ & -0.011 & 0.002 & -7.108 & 0.000 \\
\hline
\end{tabular}

Model fit information: $\chi^{2}=2849.448, \chi 2 / \mathrm{df}=10.140, \mathrm{n}=70740, \quad \mathrm{RMSEA}=.011, \quad$ CFI=.976, TLI=.972, WRMR=2.133

*Reference category of gender (female), for_born and n_speak (native), and lang_t (speaking the same language of the test.

$* * \rightarrow$ indicates causal effects; $\leftrightarrow$ covariance; and $\leftarrow$ indicates observed item used to construct latent variable. ***All the parameters correspond at 5 decimals points to bootstrap and replicate weights estimation.

Source: PIAAC 2013, Authors' calculations. 
To sum up, education has an important mediating role in the configuration of adult skills. As a general predictor of these skills, it affects literacy directly, and it strongly influences the practice of skills. However, this relationship and the effectiveness of education in terms of literacy is quite variable, as cross-country analyses have shown. This could be due in part to the high correlation between lower educational attainment and lower skills levels. Furthermore, structural elements, such as family background, play an important role in shaping education, skills use in the workplace and, hence, labour market status. Moreover, a relevant residual influence of family background is associated with adult skills, illustrating how unequal access among families to resources has a strong effect at later stages in life, having a marked influence on education and skill outcomes.

\section{Conclusion}

The mastery of certain key skills is deemed essential for social inclusion and participation in a constantly changing, knowledge-based economy. Skills are socially acquired in a wide variety of ways and the work of the individual is not simply another production factor, rather the ability to perform a job is conceived and constructed socially. A plurality of factors affects the acquisition and loss of skills and the interaction of these factors highlights the need for a complex analytical approach. Our paper has sought to recognise the importance of the interrelation of this array of factors in the configuration of adult skills in OECD countries. It has developed a hypothetical model of the acquisition of adult skills and accounted for the complex relationship between diverse constructs. However, we should remind readers that our findings need to be read in the light of the study's limitations. First, it has only been possible to analyse associations, and not causal estimates, given the currently available data. Second, this study has not considered the particularities of cross-country differences in adult skill levels and their dispersion; hence, caution should be exercised when interpreting the implications of these results as they do not provide specific evidence for individual countries in the PIAAC study.

However, our findings support the argument that there are structural elements of common configuration underpinning the acquisition of adult skills among the OECD members. Our results indicate that family background, age and education intervene strongly in the development of these skills, although these effects may vary at the crossnational level. The importance of family background is persistent in the configuration of skills and the factor has both a direct and relevant influence on education and literacy, its 
effect being manifest in the shaping of social outcomes during later stages of life. The primary source of inequality in educational opportunities lies in the unequal access to a range of resources that exists between families of different backgrounds. As a general predictor of adult skills, education affects literacy directly and it is strongly associated with skills use. Education likewise plays an important role in mediating the effects of family origin on an individual's career and literacy. Even after controlling for all the other variables in the model, the use of skills at home and in the workplace still have notable effects on literacy. This points to some evidence regarding the consequences for skills of long, sustained periods of high unemployment. The evidence we report, therefore, supports policies aimed at reducing unequal opportunities in education and at developing high quality, life-long learning programs that can promote the capacity for individual growth and experimentation. 


\section{References}

Andrew, P. et al., 2014. OECD and Pisa tests are damaging education worldwide. The Guardian.

Arrow, K.J., 1973. Higher education as a filter. Journal of Public Economics, 2(3), pp.193216.

Baron, J.N. \& Bielby, W.T., 1980. Bringing the Firms Back in: Stratification, Segmentation, and the Organization of Work. American Sociological Review, 45(5), pp.737-765.

Barone, C. \& Van de Werfhorst, H.G., 2011. Education, cognitive skills and earnings in comparative perspective. International Sociology, 26(4), pp.483-502.

Becker, G., 1964. Human Capital: A Theoretical and Empirical Analysis, with Special Reference to Education, Chicago: University of Chicago.

Bell, D., 1999. The Coming of Post-Industrial Society: A Venture in Social Forecasting, New York: Basic Books.

Black, S.E., Devereux, P.J. \& Salvanes, K.G., 2005. Why the apple doesn't fall far: understanding intergenerational transmission of human capital. The American Economic Review, 95(1), pp.437-449.

Blau, P.M. \& Duncan, O.D., 1967. The American occupational structure, New York: Wiley Press.

Boudon, R., 1973. L’inégalité des chances, La mobilité sociale dans les sociétés industrielles, Paris: Colin.

Bourdieu, P. \& Passeron, J.-C., 1964. Les héritiers, Paris: Minuit.

Braga, M., Checchi, D. \& Meschi, E., 2013. Educational policies in a long-run perspective. Economic Policy, 28(73), pp.45-100.

Breen, R. \& Karlson, K.B., 2014. Education and Social Mobility: New Analytical Approaches. European Sociological Review, 30(1), pp.107-118.

Brown, P., Lauder, H. \& Ashton, D., 2008. Education, globalisation and the future of the knowledge economy. , 7(2), pp.131-156.

Brown, P., Lauder, H. \& Ashton, D., 2011. The Global Auction: The Broken Promises of Education, Jobs, and Incomes Oxford Uni., Oxford: Oxford University Press.

Bukodi, E. \& Goldthorpe, J.H., 2012. Decomposing "social origins": The effects of parents' class, status, and education on the educational attainment of their children. European Sociological Review, 29(5), pp.1024-1039.

Bukodi, E. \& Goldthorpe, J.H., 2012. Decomposing "Social Origins": The Effects of Parents' Class, Status, and Education on the Educational Attainment of Their Children. European Sociological Review, 29(5), pp.1024-1039.

Calero, J., Murillo Huertas, I. \& Raymond Bara, J.L., 2016. Education, age and skills: an analysis using the PIAAC survey, Barcelona.

Carbonaro, W., 2007. The effects of education and cognitive skill on earnings: How much do occupations and jobs matter? Research in Social Stratification and Mobility, 25(1), pp.57-71.

Chevalier, A. et al., 2013. The impact of parental income and education on the schooling of their children. IZA Journal of Labor Economics, 2(1), p.8.

Coleman, J., 1966. Equality of Educational Opportunity. Available at: http://files.eric.ed.gov/fulltext/ED012275.pdf.

Collins, H. \& Evans, R., 2007. Rethinking Expertise T. U. of C. Press, ed., Chicago.

Collins, R., 1979. The Credential Society: An Historical Sociology of Education and Stratification, New York: Academic Press. 
Cunha, F. \& Heckman, J., 2007. The Technology of Skill Formation. NBER Working Paper No. 12840.

Cunha, F., Heckman, J. \& Schennach, S., 2010. Estimating the Technology of Cognitive and Noncognitive Skill Formation. NBER Working Papers.

Davis, K. \& Moore, W.E., 1945. Some Principles of Stratification. American Sociological Review, 10(2), pp.242-249.

Desjardins, R., 2003. Determinants of literacy proficiency: A lifelong-lifewide learning perspective. International Journal of Educational Research, 39, pp.205-245.

Desjardins, R. \& Warnke, A.J., 2012. Ageing and skills. A Review and analysis of skill gain and skill loss over the lifespan and over time, Paris.

Desrosières, A., 2008. La statistique, outil de gouvernement et outil de preuve. L'argument statistique I : Pour une sociologie historique de la quantification, pp.7-20.

Dronkers, J. \& Heus, M. de, 2013. Immigrants' children scientific performance in a double comparative design: the influence of origin, destination, and community. In PISA, Power, and Policy: the emergence of global educational governance, edited by H.-D. Meyer \& A. Benevot. Oxford: Symposium Books. pp. 247-265.

Dronkers, J. \& Velden, R. Van Der, 2013. Integration and Inequality in Educational Institutions. , pp.71-98.

Erikson, R. \& Goldthorpe, J.H., 1992. The constant flux: a study of class mobility in industrial societies, London: Clarendon Press.

Espeland, W. \& Sauder, M., 2007. Rankings and Reactivity. American Journal of Sociology, 113(1), pp.1-40.

EU high level group of experts on literacy, 2012. Act now!, Luxembourg.

Flyvberg, B., 2001. Making Social Science Matter. Why social inquiry fails and how it can succeed again, Cambridge: Cambridge University Press.

Gal, I. \& Tout, D., 2014. Comparison of PIAAC and PISA Frameworks for Numeracy and Mathematical Literacy, Paris.

Ganzeboom, H.B.G., de Graaf, P.M. \& Treiman, D.J., 1992. A standard international socioeconomic index of occupational status. Social Science Research, 21, pp.1-56.

Gebhardt, E. \& Adams, R.J., 2007. The influence of equating methodology on reported trends in PISA. Journal of Applied Measurement, 8(3), pp.305-322.

Goldstein, H., 2004. International comparisons of student attainment: some issues arising from the PISA study. Assessment in Education: Principles, Policy \& Practice, 11(3), pp.319-330.

Grek, S., 2009. Governing by numbers: the PISA "effect" in Europe. Journal of Education Policy, 24, pp.23-37.

Grek, S., 2010. International Organisations and the Shared Construction of Policy "Problems": problematisation and change in education governance in Europe. European Educational Research Journal, 9(3), p.396.

Guile, D. \& Okumoto, K., 2007. "We are trying to reproduce a crafts apprenticeship": from Government Blueprint to workplace generated apprenticeship in the knowledge economy. Journal of Vocational Education \& Training, 59(4), pp.551-574.

Haller, A.O. \& Portes, A., 1973. Status Attainment Processes. Sociology of Education, 46(1), pp.51-91.

Hanushek, E.A. et al., 2013. Returns to skills around the world: Evidence from PIAAC. NBER, Working Pa.

Hanushek, E.A. \& Kimko, D., 2000. Schooling, labor-force quality, and the growth of nations. American Economic Review, 90(5), pp.1184-1208.

Hanushek, E.A. \& Wößmann, L., 2008. The Role of Cognitive Skills in Economic Development. Journal of Economic Literature, 46(3), pp.607-668. 
Harmon, C., Oosterbeek, H. \& Walker, I., 2003. The Returns to Education: Microeconomics. Journal of Economic Surveys, 17(2), pp.115-156.

Heckman, J.J., 1995. Lessons from the Bell Curve. Journal of Political Economy, 103(5), p.1091.

Hoskins, B. et al., 2014. Inequalities in the education system and the reproduction of socioeconomic disparities in voting in England, Denmark and Germany: the influence of country context, tracking and self-efficacy on voting intentions of students age 1618. Compare: A Journal of Comparative and International Education, (June), pp.124.

ILO, 2011. A Skilled Workforce for Strong, Sustainable and Balanced Growth: A G20 Training Strategy, Geneva.

Isphording, I.E., 2014. Disadvantages of linguistic origin-Evidence from immigrant literacy scores. Economics Letters, 123(2), pp.236-239.

Jerrim, J. \& Macmillan, L., 2015. Income Inequality, Intergenerational Mobility, and the Great Gatsby Curve: Is Education the Key? Social Forces, 94(2), pp.1-29.

Kerckhoff, A.C., 2001. Education and Social Stratification Processes in Comparative Perspective. Sociology of Education, 74, pp.3-18.

Kline, R.B., 2016. Principles and practices of structural equation modelling 4th ed., New York - London: The Guilford Press.

Krahn, H. \& Lowe, G.S., 1998. Literacy utilization in Canadian workplaces, Ottawa.

Lamont, M., 2012. Toward a Comparative Sociology of Valuation and Evaluation. Annual Review of Sociology, 38, pp.201-221.

Marks, G.N., 2006. Accounting for immigrant non-immigrant differences in reading and mathematics in twenty countries. Ethnic and Racial Studies, 28(3), pp.925-946.

Meyer, H.-D. \& Benavot, A., 2013. PISA, Power, and Policy: the emergence of global educational governance, Oxford: Symposium Books.

OECD, 2013a. Better Skills Better Jobs Better Lives, Paris: OECD Publishing.

OECD, 2012. Literacy, Numeracy and Problem Solving in Technology-Rich Environments: Framework for the OECD Survey of Adult Skills,

OECD, 2000. Literacy in the information age. Oecd \& Statistics Canada. Available at: http://www.oecd.org/edu/skills-beyond-school/41529765.pdf.

OECD, 2013b. Technical Report of the Survey of Adult Skills (PIAAC), Paris.

Oreopoulos, P. \& Salvanes, K.G., 2011. Priceless: The Nonpecuniary Benefits of Schooling. Journal of Economic Perspectives, 25(1), pp.159-184.

Rammstedt, B. et al., 2012. PIAAC 2012 : Overview of the Main Results.

Reich, R.B., 1992. The Work of Nations: Preparing Ourselves for 21st Century Capitalism, Vintage.

Saris, W.E., Satorra, A. \& van der Veld, W.M., 2009. Testing structural equation models or detection of misspecifications? Structural Equation Modeling. Vol 16(4), 16(October), pp.561-582.

Spence, M., 1973. Job Market Signaling. The Quarterly Journal of Economics, 87(3), pp.355-374.

Stoet, G. \& Geary, D.C., 2015. Sex differences in academic achievement are not related to political, economic, or social equality. Intelligence, 48, pp.137-151.

Svend, K., 2011. Is the foundation under PISA solid? A critical look at the scaling model underlying international comparisons of student attainment, Copenhagen.

Thurow, L.C., 1975. Generating inequality, New York: McMillian Press.

De Witte, K. et al., 2013. The Impact of Institutional Context, Education and Labour Market Policies on Early School Leaving: A comparative analysis of EU countries. European Journal of Education, 48(3), pp.331-345. 
Wößmann, L., 2003. Specifying Human Capital. Journal of Economic Surveys, 17(3), pp.239-270. 